Mechani cal properti es of neut ron- i rradi at ed vanadi um al I oys i $n$ a I i qui $d$ - sodi um envi ronment

\begin{tabular}{|l|l|}
\hline 著者 & $\begin{array}{l}\text { KURO WA Hi t oshi, FUKUMOTO Ken- i chi, MARUI } \\
\text { M nor u, NATSUl H deki, Q U Xu }\end{array}$ \\
\hline $\begin{array}{l}\text { j our nal or } \\
\text { publ i cat i on t i t l e }\end{array}$ & Jour nal of Nucl ear Nat er i al s \\
\hline vol une & $386-388$ \\
\hline page range & $594-597$ \\
\hline year & $2009-04-30$ \\
\hline URL & ht t p: //hdl . handl e. net /10098/1982 \\
\hline
\end{tabular}




\title{
Mechanical properties of neutron-irradiated vanadium alloys in a liquid-sodium
} environment

\author{
Hitoshi Kuroiwa $^{1}$, Ken-ichi Fukumoto ${ }^{1}$, Minoru Narui ${ }^{2}$, Hideki Matsui ${ }^{2}$ and Xu Qiu ${ }^{3}$ \\ ${ }^{1}$ Graduate School of Nuclear Power and Energy Safety Engineering: University of Fukui, Fukui \\ 910-8507, Japan \\ ${ }^{2}$ Institute for Materials Research : Tohoku University, Sendai 980-8577, Japan \\ ${ }^{3}$ KUR, Kyoto Univ. Kumatori 590-0494, Japan \\ Corresponding Author \\ Ken-ichi FUKUMOTO
}

Bunkyo 2-1-1, Fukui, 910-8507 Japan

TEL \& FAX : +81-776-27-9712

e-mail : fukumoto@mech.fukui-u.ac.jp

PACS Code,

61.80. Hg Neutron radiation effects

61.82.Bg Radiation effects on metals and alloys

91.60.Ed Crystal structure and defects, microstructure 


\title{
Mechanical properties of neutron-irradiated vanadium alloys in a
}

\section{liquid-sodium environment}

\author{
Hitoshi Kuroiwa $^{1}$, Ken-ichi Fukumoto ${ }^{1}$, Minoru Narui ${ }^{2}$, Hideki Matsui ${ }^{2}$ and Xu Qiu ${ }^{3}$ \\ ${ }^{1}$ Graduate School of Nuclear Power and Energy Safety Engineering: University of Fukui, Fukui \\ 910-8507, Japan \\ ${ }^{2}$ Institute for Materials Research : Tohoku University, Sendai 980-8577,Japan \\ ${ }^{3}$ KUR, Kyoto Univ. Kumatori 590-0494, Japan
}

\section{Abstract}

Vanadium alloys, including the highly purified V-4Cr-4Ti alloy called NIFS-Heat2, in the form of sodium-enclosed irradiation capsules, were irradiated up to a damage level of $5 \mathrm{dpa}$ in the Joyo reactor at temperatures from 395 to $601^{\circ} \mathrm{C}$.

An increase of the ductile-brittle transition temperature (DBTT) by neutron irradiation and irradiation hardening were observed. No significant loss of ductility was observed even for irradiation at 395 and $450^{\circ} \mathrm{C}$. The addition of titanium to $\mathrm{V}-\mathrm{Cr}$ alloys was effective for irradiation hardening at high temperature. Hydrogen uptake in the cleaning process during dismantling of the irradiation capsules caused ductility loss of the highly purified V-4Cr-4Ti alloys; the alloys recovered their ductility when they were annealed at $400^{\circ} \mathrm{C}$ in vacuum. The uniform formation of $\mathrm{Ti}(\mathrm{OCN})$ precipitate was suppressed in highly purified $\mathrm{V}-4 \mathrm{Cr}-4 \mathrm{Ti}$ alloys irradiated in Joyo in a 
liquid-sodium environment.

\section{Introduction}

Vanadium alloys are candidate materials for blanket structural materials in fusion reactors,

but knowledge about their mechanical properties at high temperatures during neutron irradiation is limited and there are uncertainties, such as the interstitial impurity content of the specimens, that may influence the results. Recently, the technology for material irradiation in a liquid-metal environment has been developed and irradiation experiments in various liquid-metal environments have been performed for vanadium alloys [1,2]. The environmental and irradiation effects on the mechanical properties of the vanadium alloys should be distinguished independently in order to understand the essential behavior of the alloys during irradiation for fusion reactor applications. The objective of this study is to investigate the mechanical properties and microstructural changes of vanadium alloys, including the highly purified $\mathrm{V}-4 \mathrm{Cr}-4 \mathrm{Ti}$ alloy called NIFS-Heat2, during neutron irradiation. In this study, tensile tests, Charpy impact tests and microstructural observations were carried out for $\mathrm{V}-4 \mathrm{Cr}-4 \mathrm{Ti}$ alloys and vanadium binary alloys.

\section{Experimental procedure}


Various kinds of specimens, including $1.5 \mathrm{~mm}$ Charpy V-notched specimens, miniaturized tensile (SSJ) specimens and TEM specimens, were prepared for the Joyo experiments. The materials included unalloyed vanadium, vanadium binary alloys (with $\mathrm{Cr}$, Ti solute atoms up to 5 wt.\%), and vanadium ternary alloys ( $\mathrm{V}-4 \mathrm{Cr}-\mathrm{xTi}, \mathrm{x}=0.1$ to 4$)$. Tables of the chemical components have been given in previous papers $[3,4]$. The $\mathrm{V}-4 \mathrm{Cr}-4 \mathrm{Ti}$ alloy used in this study was produced by NIFS and Taiyo Koko Co. and is designated NIFS-Heat2 [5]. The size of the SSJ specimens was $16 \times 4 \times 0.25 \mathrm{~mm}$. The tensile specimens were prepared from unalloyed vanadium, $\mathrm{V}-5 \mathrm{Cr}$, $\mathrm{V}-4 \mathrm{Cr}-0.1 \mathrm{Ti}, \mathrm{V}-4 \mathrm{Cr}-1 \mathrm{Ti}$ and $\mathrm{V}-4 \mathrm{Cr}-4 \mathrm{Ti}$. Charpy specimens were prepared from $\mathrm{V}-4 \mathrm{Cr}-4 \mathrm{Ti}$ NIFS-Heat alloys. The notch of the Charpy specimens was machined with the plane of crack propagation perpendicular to the rolling direction. The angle of the notch was $30^{\circ}$ with a notch depth of $0.45 \mathrm{~mm}$ and a root radius of $0.20 \mathrm{~mm}$. The TEM and SSJ tensile specimens were punched and annealed at $1100^{\circ} \mathrm{C}$ for $2 \mathrm{~h}$ after a degassing treatment at $600^{\circ} \mathrm{C}$ for $0.5 \mathrm{~h}$ in a vacuum of $\sim 1 \times 10^{-4} \mathrm{~Pa}$. The $1.5 \mathrm{~mm}$ Charpy V-notched specimens were annealed at $1000^{\circ} \mathrm{C}$ for $2 \mathrm{~h}$. The specimens were irradiated in the Joyo reactor in the temperature range 450 to $650^{\circ} \mathrm{C}$ with a total neutron dose from 0.47 to $2.1 \times 10^{26} \mathrm{n} / \mathrm{m}^{2}$. In the previous study, the ratio of the damage level, dpa, to the neutron dose $\Phi^{\text {tot }}$ in pure vanadium in the Joyo MK-II was given by the relationship 2.5 $\times 10^{-26} \mathrm{dpa} / \Phi^{\text {tot }}[6]$. The estimated damage level ranged from 1.2 to $5.3 \mathrm{dpa}$. Table 1 shows the irradiation conditions in the Joyo experiments Sodium-enclosed irradiation capsules were 
developed in order to homogenize the temperature on large specimens and prevent the invasion of interstitial impurities from the sodium environment during irradiation. Detailed additional information about the sodium-enclosed capsule installation in the Joyo reactor is given elsewhere [1]. After dismantling the sodium-enclosed capsules and cleaning the specimen surface, tensile and Charpy impact tests were performed at the Oarai Center in IMR/Tohoku University. TEM observations were performed using a JEOL-2010FX in KUR, Kyoto University.

\section{Results}

\section{Tensile and Charpy impact tests}

Figure 1 shows the results of Charpy impact tests for V-4Cr-4Ti alloys irradiated at 395 and $449^{\circ} \mathrm{C}$. The absorbed energy was normalized by the ligament size, which is $B \times b=1.05 \times 1.2$ $\mathrm{mm}^{2}$. The ductile-brittle transition temperature (DBTT) and the upper shelf energy (USE) of unirradiated V-4Cr-4Ti NIFS-Heat2 alloys were $<-196^{\circ} \mathrm{C}$ and $0.4 \mathrm{~J} / \mathrm{m}^{3}$, respectively [7]. The USE values for $\mathrm{V}-4 \mathrm{Cr}-4 \mathrm{Ti}$ alloys irradiated in Joyo were lower than for unirradiated ones, and the DBTT increased to -80 and $10^{\circ} \mathrm{C}$ for 395 and $449^{\circ} \mathrm{C}$ irradiation, respectively.

Figure 2 shows the neutron-dose dependence of the yield stress from the results of tensile tests at room temperature for pure vanadium and $\mathrm{V}-(4-5) \mathrm{Cr}-\mathrm{xTi}(\mathrm{x}=0$ to 4$)$. In pure vanadium, significant irradiation hardening occurred in the low-temperature regime from 400 to $450^{\circ} \mathrm{C}$, but 
the hardening at $600^{\circ} \mathrm{C}$ was small. The addition of chromium was quite effective for increasing the irradiation hardening at low temperatures. The addition of titanium to $\mathrm{V}-\mathrm{Cr}$ alloys increased the yield stress at 450 and $600^{\circ} \mathrm{C}$ irradiation. Irradiation hardening increased significantly at $450^{\circ} \mathrm{C}$ by the addition of $0.1 \%$ titanium, and the stress level of irradiation hardening might be saturated at a neutron fluence of $7 \times 10^{25} \mathrm{n} / \mathrm{m}^{2}(\sim 1.8 \mathrm{dpa})$. Further addition of titanium apparently increased the irradiation hardening at $600^{\circ} \mathrm{C}$ and the hardening might be saturated above a neutron fluence of $6 \times 10^{25} \mathrm{n} / \mathrm{m}^{2}(-1.5 \mathrm{dpa})$.

A reduction in ductility of the vanadium alloys could be seen for all irradiation conditions. However, it is necessary to handle the ductility-loss data for vanadium alloys carefully because of hydrogen uptake into the specimens during cleaning of the specimen surface after dismantling the sodium-enclosed irradiation capsules. It has been reported that hydrogen absorption reduced the uniform elongation without hardening and caused a sudden drop of flow stress in tensile tests [8]. In order to eliminate the effect of hydrogen uptake, the irradiated $\mathrm{V}-4 \mathrm{Cr}-4 \mathrm{Ti}$ vanadium alloys were heat treated for $5 \mathrm{~h}$ at $400^{\circ} \mathrm{C}$ in vacuum. Table 2 shows the changes of the mechanical properties of V-4Cr-4Ti NIFS-Heat2 alloys tested at room temperature before and after heat treatment. Sudden drops after yielding or at flow stress were not observed, and recovery of uniform elongation could be seen in the heat-treated specimens. It is necessary todistinguish 
between the essential behavior of ductility loss and the effect of hydrogen uptake in $\mathrm{V}-4 \mathrm{Cr}-4 \mathrm{Ti}$

alloys in liquid-metal environments during neutron irradiation.

\section{Microstructural analysis}

Figure 3 shows a typical example of the microstructure of $\mathrm{V}-4 \mathrm{Cr}-4 \mathrm{Ti}$ alloy and pure vanadium irradiated in the Joyo reactor. Dislocation loops and $\mathrm{Ti}(\mathrm{OCN})$ precipitates were the dominant microstructures for $\mathrm{V}-4 \mathrm{Cr}-4 \mathrm{Ti}$ alloys irradiated at 400 and $450^{\circ} \mathrm{C}$. There were high densities of rafting loops, and tiny precipitates were distributed locally around the loop-rafting area. At $600^{\circ} \mathrm{C}$, dislocation loops and $\mathrm{Ti}(\mathrm{OCN})$ precipitates were the dominant microstructures for $\mathrm{V}-4 \mathrm{Cr}$-4Ti with a neutron dose of $0.61 \times 10^{26} \mathrm{n} / \mathrm{m}^{2}$. The structure of the dislocation loops evolved and changed into a tangled dislocation structure with increasing neutron dose. However, the precipitates were dissipated in V-4Cr-4Ti alloys irradiated with a neutron dose of $1.3 \times 10^{26} \mathrm{n} / \mathrm{m}^{2}$.

In pure vanadium, voids were observed; their size increased and their density decreased when the irradiation temperature and neutron dose increased. Dislocations were coarsened and the dislocation density of pure vanadium decreased when the irradiation temperature and neutron dose increased. The microstructure of pure vanadium in this study had the same features as pure vanadium irradiated in FFTF reactor at 430 to $600^{\circ} \mathrm{C}$ to a damage level ranging from 15 to $27 \mathrm{dpa}$ [9]. 


\section{Discussion}

Significant increases of DBTT for $\mathrm{V}-4 \mathrm{Cr}-4 \mathrm{Ti}$ irradiated at low temperatures have been reported in previous work $[10,11]$. Low ductility (less than 1\%) and significant hardening up to 800 MPa were reported for irradiated $\mathrm{V}-4 \mathrm{Cr}-4 \mathrm{Ti}$ alloys, along with a significant increase of DBTT in V-4Cr-4Ti irradiated at $400^{\circ} \mathrm{C}$ with a damage level of 4-6dpa [11]. This study also showed significant hardening and low ductility of $5-10 \%$ in the $\mathrm{V}-4 \mathrm{Cr}-4 \mathrm{Ti}$ alloy after irradiation to $1 \mathrm{dpa}$ at $395^{\circ} \mathrm{C}$. Tiny precipitates were formed around rafted loops and were distributed inhomogeneously. Most of the precipitates in $\mathrm{V}-4 \mathrm{Cr}-4 \mathrm{Ti}$ irradiated at temperatures less than $400^{\circ} \mathrm{C}$ were formed homogeneously, accompanied by dislocation loops [11, 12]. It was believed that the inhomogeneous distribution of precipitates was caused by redistribution during irradiation: some pre-existing precipitates were dissolved into the matrix during irradiation and the alloy elements diffused and nucleated new precipitates around the pre-existing ones. The NIFS-Heat2 alloys have a smaller impurity level than any of the previous $\mathrm{V}-4 \mathrm{Cr}-4 \mathrm{Ti}$ alloys and the uniform formation of precipitates in the matrix might be suppressed in this study. The effect of impurity reduction on mechanical- property changes under irradiation can be seen in the redistribution of the irradiation-induced precipitates and the recovery of ductility in V-4Cr-4Ti alloys. Therefore, the purification of these alloys is very important for the improvement of their mechanical properties at 
low irradiation temperatures.

\section{Summary}

Vanadium alloys, including the highly purified V-4Cr-4Ti alloy called NIFS-Heat2, were irradiated up to $5 \mathrm{dpa}$ in the Joyo reactor in liquid sodium in the temperature range 395 to $601^{\circ} \mathrm{C}$. An increase of the DBTT by neutron irradiation and irradiation hardening were observed. Significant loss of ductility was observed during irradiation at 395 and $450^{\circ} \mathrm{C}$. The addition of titanium to the $\mathrm{V}$-Cr alloys was effective for irradiation hardening at high temperatures. Hydrogen uptake in the cleaning process during dismantling of the irradiation capsules caused ductility loss in the highly purified V-4Cr-4Ti alloys; the ductility was recovered by annealing at $400^{\circ} \mathrm{C}$ in vacuum. The formation of $\mathrm{Ti}(\mathrm{OCN})$ precipitates was not uniform, which resulted in a significant loss of ductility in the highly purified $\mathrm{V}-4 \mathrm{Cr}$-4Ti irradiated in the Joyo reactor in a liquid-sodium environment. 
References

[1] K. Fukumoto, N. Narui, H. Matsui et al., to be published in J. Nucl. Sci. Tech. (2008)

[2] D. K. Felde and R. J. Wallace, DOE-ER-0313/38 (2005) 159

[3] K. Fukumoto, A. Kimura, and H. Matsui, J. Nucl. Mater., .258-263 (1998) 1431

[4] K. Fukumoto, T. Morimura et al., J. Nucl. Mater., 239 (1996) 170

[5] T. Muroga, T. Nagasaka, A. liyoshi et al., J. Nucl. Mater. 283-287 (2000) 711.

[6] PNCT-N9440 90-006 (1990) in Japanese

[7] T. Nagasaka, N. J. Heo, T. Muroga et al., J. Nucl. Mater. 329-333 (2004) 1539.

[8] K.Natesan and W. K. Soppet, J. Nucl. Mater., 283-287 (2000) 1316

[9] K. Fukumoto, H. M. Chung, J. Gazda et al., Sci. Rep. Res. Inst. Tokohu Univ. A, Phys. Chem.

Metall., 45 (1997) 49

[10] K. Fukumoto, H. Matsui, H. Tsai et al., J. Nucl. Mater., 283-287 (2000) 492

[11] S. J. Zinkle, H. Matsui, D. L. Smith et al., J. Nucl. Mater., 258-263 (1998) 205

[12] P. M. Rice and S. J. Zinkle, J. Nucl. Mater., 258-263 (1998) 1414 


\section{Figure captions}

Fig.1. Test-temperature dependence of absorbed energy for Charpy impact testing of NIFS-Heat2 V-4Cr-4Ti alloys irradiated in the Joyo reactor at 395 and $449^{\circ} \mathrm{C}$.

Fig.2. Dependence of yield stress on neutron dose for pure $\mathrm{V}, \mathrm{V}-5 \mathrm{Cr}, \mathrm{V}-4 \mathrm{Cr}-0.1 \mathrm{Ti}, \mathrm{V}-4 \mathrm{Cr}-1 \mathrm{Ti}$ and $\mathrm{V}-4 \mathrm{Cr}-4 \mathrm{Ti}$ alloys in tensile tests.

Fig.3. Microstructures of $\mathrm{V}-4 \mathrm{Cr}-4 \mathrm{Ti}$ alloy and pure vanadium irradiated in the Joyo reactor. The irradiation temperature and dose in units of $10^{26} \mathrm{n} / \mathrm{m}^{2}$ are given for each column. 


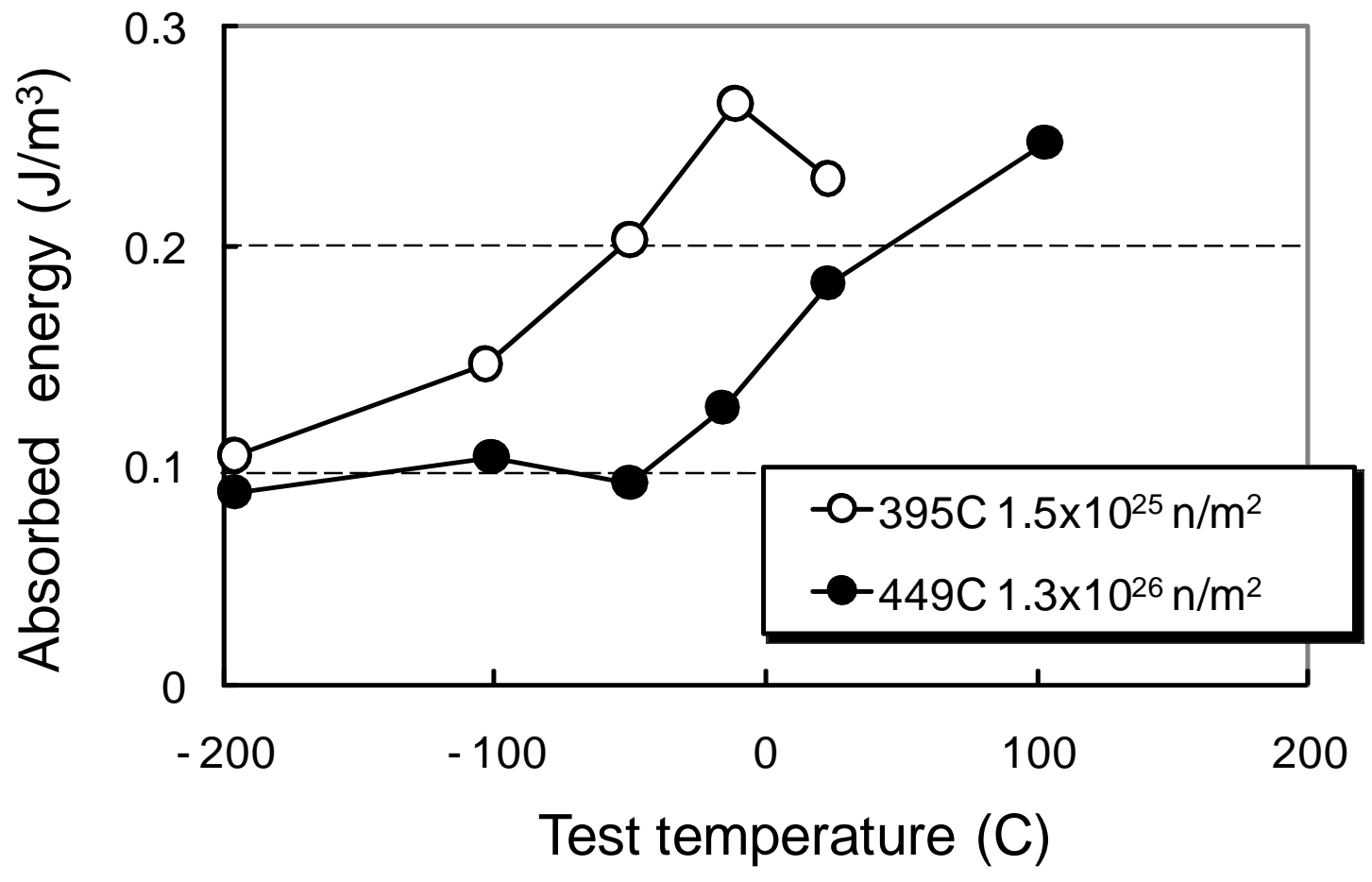

Fig.1 one column 

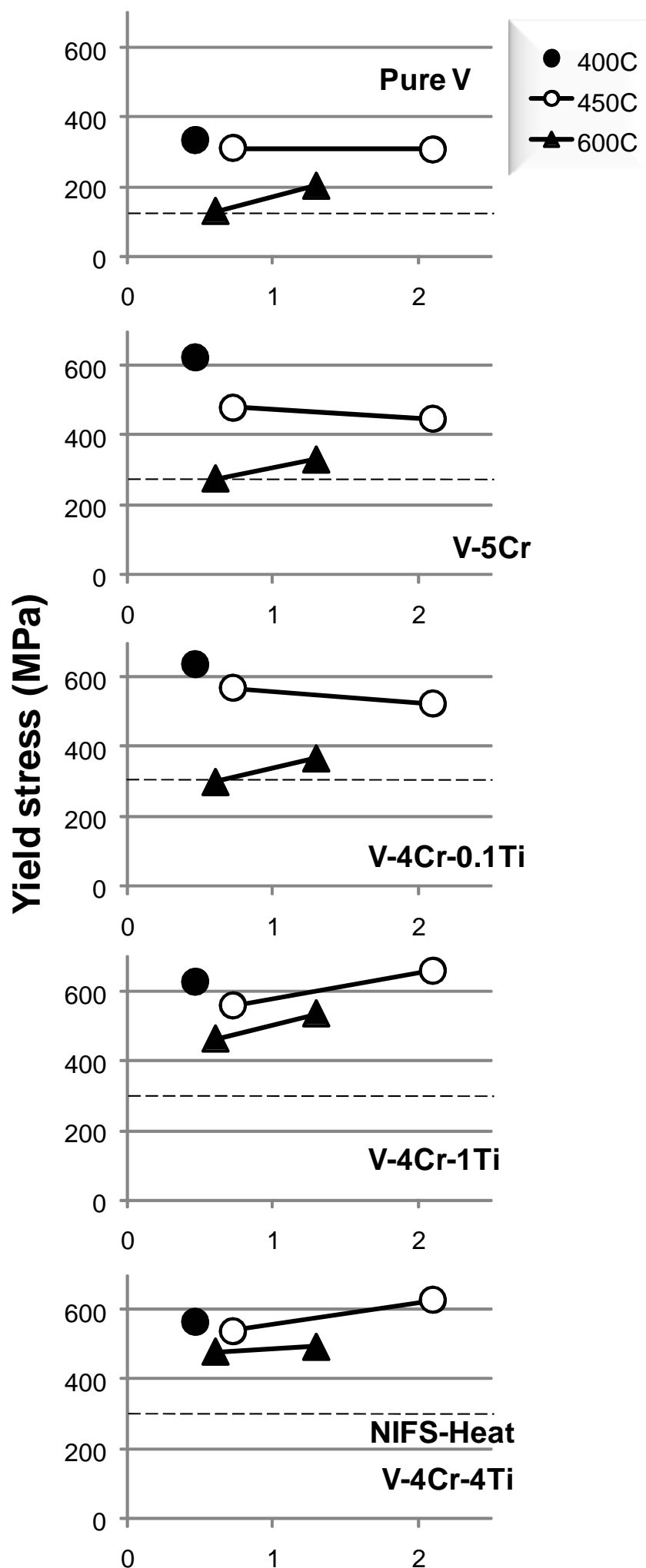

Total neutron dose $\left(\times 10^{26} \mathrm{n} / \mathrm{m}^{2}\right)$

Fig.2. one column 

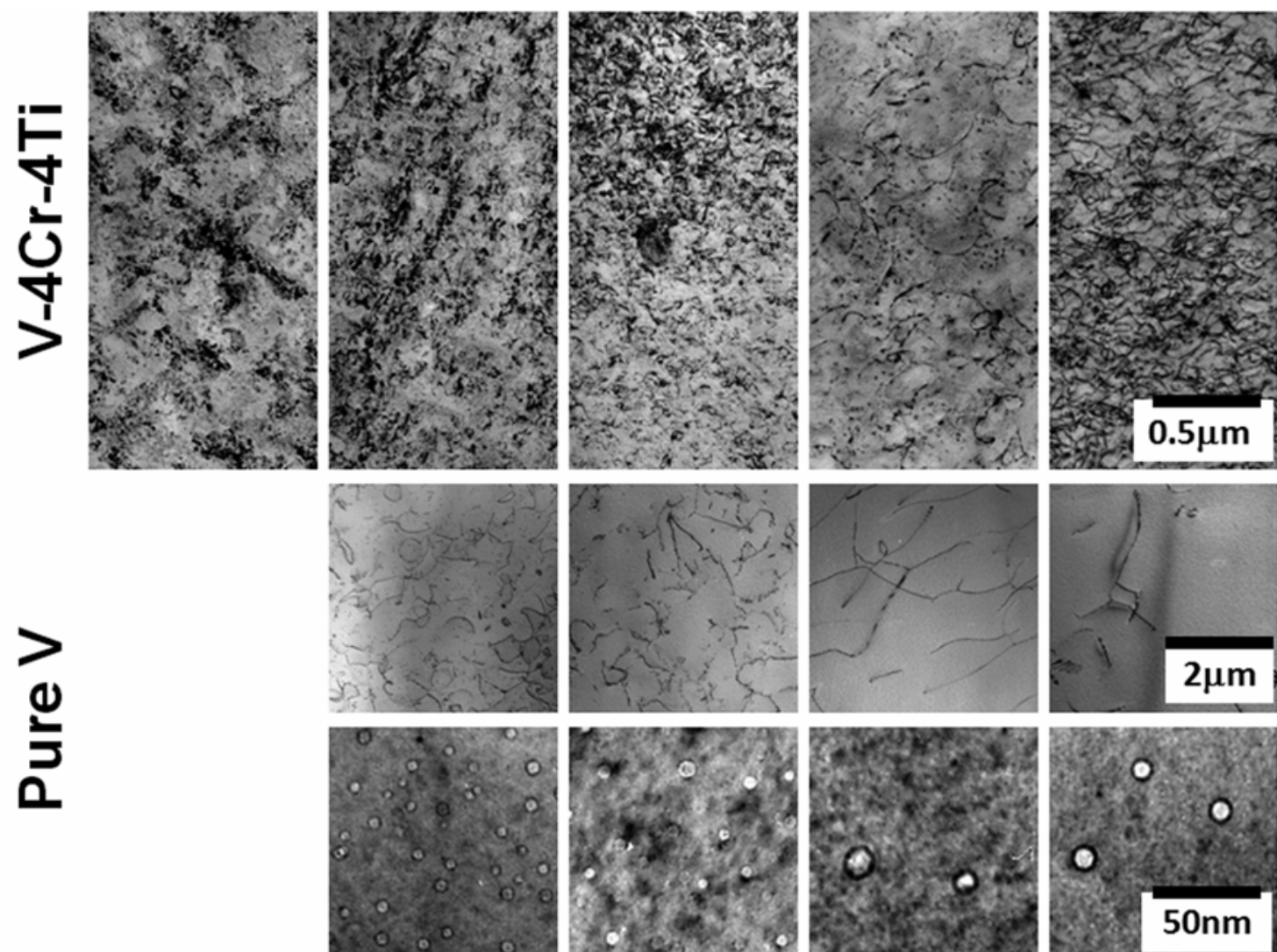

$395 \mathrm{C}$

458C

449C

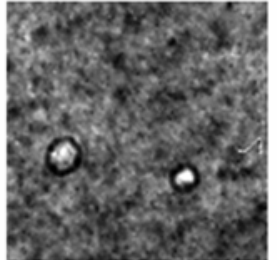

598C

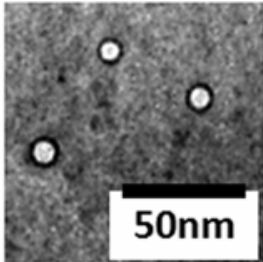

0.47

0.72

2.1

0.61

592C

1.3

Fig.3. two column 
Table 1 Irradiation conditions in the Joyo reactor.

\begin{tabular}{|l|l|l|l|}
\hline $\begin{array}{l}\text { Irradiation } \\
\text { temperature }\left({ }^{\circ} \mathrm{C}\right)\end{array}$ & $\begin{array}{l}\text { Neutron dose }(\mathrm{E}>0.1 \mathrm{MeV}) \\
\left(\times 10^{26} \mathrm{n} / \mathrm{m}^{2}\right)\end{array}$ & $\begin{array}{l}\text { Total neutron dose } \\
\left(\times 10^{26} \mathrm{n} / \mathrm{m}^{2}\right)\end{array}$ & $\begin{array}{l}\text { Estimated damage } \\
\text { level (dpa) }\end{array}$ \\
\hline 395 & 0.15 & 0.47 & 1.2 \\
\hline 458 & 0.24 & 0.72 & 1.8 \\
\hline 449 & 1.3 & 2.1 & 5.3 \\
\hline 598 & 0.32 & 0.61 & 1.5 \\
\hline 592 & 0.67 & 1.3 & 3.3 \\
\hline 748 & 0.78 & 1.5 & 3.8 \\
\hline
\end{tabular}

Table 2 Changes of mechanical properties for NIFS-Heat alloys after hydrogen-removing treatment

\begin{tabular}{|c|c|c|c|c|c|c|c|c|c|c|}
\hline & & \multicolumn{3}{|c|}{ As -irradiated } & \multicolumn{3}{c|}{ H-removed } & \multicolumn{3}{c|}{$\begin{array}{c}\text { Change after } \\
\text { H-removed }\end{array}$} \\
\hline $\mathrm{T}\left({ }^{\circ} \mathrm{C}\right)$ & $\begin{array}{c}\text { Total neutron } \\
\text { dose }\left(\times 10^{26} \mathrm{n} / \mathrm{m}^{2}\right)\end{array}$ & $\sigma_{\mathrm{y}}$ & $\sigma_{\mathrm{UTS}}$ & $\varepsilon_{\cup}$ & $\sigma_{\mathrm{y}}$ & $\sigma_{\mathrm{UTS}}$ & $\varepsilon_{\mathrm{U}}$ & $\Delta \sigma_{\mathrm{y}}$ & $\Delta \sigma_{\mathrm{UTS}}$ & $\Delta \varepsilon_{\mathrm{U}}$ \\
\hline $\mathrm{RT}$ & & 320 & 416 & 15.9 & & & & & & \\
\hline 395 & 0.47 & 566 & 615 & 7.5 & 550 & 586 & 2.8 & -16 & -29 & -4.7 \\
\hline 458 & 0.72 & 540 & 609 & 2.6 & 518 & 576 & 2.0 & -22 & -33 & -0.6 \\
\hline 449 & 2.1 & 628 & 655 & 0.8 & 569 & 609 & 4.3 & -59 & -46 & 3.5 \\
\hline 598 & 0.61 & 478 & 529 & 0.6 & 398 & 552 & 2.6 & -80 & 23 & 2.0 \\
\hline 592 & 1.3 & 495 & 556 & 1.0 & 425 & 517 & 1.3 & -70 & -39 & 0.3 \\
\hline 748 & 1.5 & 527 & 559 & 1.1 & 427 & 527 & 9.7 & -100 & -32 & 8.6 \\
\hline
\end{tabular}

